\title{
Limiting factors to oxygen transport on Mount Everest 30 years after: a critique of Paolo Cerretelli's contribution to the study of altitude physiology
}

Accepted: 24 June 2003 / Published online: 3 October 2003

(C) Springer-Verlag 2003

\begin{abstract}
In 1976, Paolo Cerretelli published an article entitled "Limiting factors to oxygen transport on Mount Everest" in the Journal of Applied Physiology. The paper demonstrated the role of cardiovascular oxygen transport in limiting maximal oxygen consumption $\left(\dot{V} \mathrm{O}_{2 \max }\right)$. In agreement with the predominant view of $\dot{V} \mathrm{O}_{2 \max }$ limitation at that time, however, its results were taken to mean that cardiovascular oxygen transport does not limit $\dot{V} \mathrm{O}_{2 \max }$ at altitude. So it was argued that the limiting factor could be in the periphery, and muscle blood flow was proposed as a possible candidate. Despite this suggestion, the conclusion generated a series of papers on muscle structural characteristics. These experiments demonstrated a loss of muscle oxidative capacity in chronic hypoxia, and thus provided an unambiguous refutation of the then widespread hypothesis that an increased muscle oxidative capacity is needed at altitude to compensate for the lack of oxygen. This analysis is followed by a short account of Cerretelli's more recent work, with a special attention to the subject of the so-called "lactate paradox".
\end{abstract}

Keywords Altitude adaptation · Humans · Muscle morphometry $\cdot$ Maximum oxygen consumption limitation · Lactate

\section{G. Ferretti}

Laboratorio di Fisiologia Umana,

Dipartimento di Scienze Biomediche e Biotecnologie,

Università di Brescia,

Viale Europa 11, 25100 Brescia, Italy

E-mail: Guido.Ferretti@medecine.unige.ch

Tel.: + 39-030-3717440

G. Ferretti

Département de Physiologie,

Centre Médical Universitaire,

Geneva, Switzerland

\section{Introduction}

In this paper some of Paolo Cerretelli's contributions to the study of man's adaptation to altitude exposure are analysed. It is not a survey of his work. In the first part I discuss the origin, the results and the consequences of what is, at least in my opinion, his most influential paper, entitled "Factors limiting oxygen transport on Mount Everest", published in the Journal of Applied Physiology in 1976 (Cerretelli 1976). I am intrigued by this paper because the conclusions arrived at were the only possible logical conclusions at that time, although they can now be considered to be intrinsically wrong. In spite of this, and despite the fact that they were not even pointing to that direction, they led to the opening of an entire new chapter of altitude physiology, that of the morphological study of muscle adaptation to altitude, to which Paolo Cerretelli, Hans Hoppeler and Hans Howald gave great impulse. Subsequently I propose a brief critical analysis of his more recent contributions to our understanding of the so-called "lactate paradox".

\section{The early years}

In 1959, Cerretelli participated as medical scientist in an expedition aimed at conquering the then virgin peak of Kanjut-Sar, in the Karakoram, organised by Guido Monzino, a remarkable figure of climber and explorer descended from a major family of the industrial bourgeoisie of Milan (see Fig. 1).

Three experiments were carried out in that expedition. The first (Cerretelli 1959) reported data on the ventilatory response to chronic hypoxia, investigated by the technique of chemical denervation of peripheral chemoreceptors that Dejours et al. (1959) had just published. In practice, the subjects, while breathing ambient air, were suddenly administered four breaths of pure oxygen. The evolution of pulmonary ventilation was then followed on the spirometer. It was shown that 


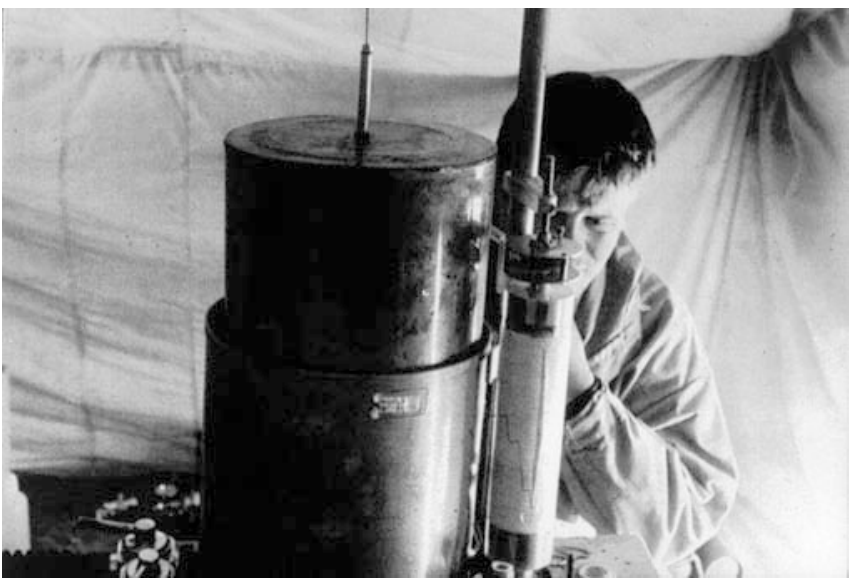

Fig. 1 Paolo Cerretelli portrayed behind a Tissot spirometer inside a tent at the base camp of Mount Kanjut-Sar, 1959

the reduction in ventilation induced by oxygen breathing was greater in chronic hypoxia than in normoxia. The same technique was resumed 25 years later for investigating the chemoreflexogenic drive of climbers who reached the highest peaks on Earth without supplementary oxygen (Oelz et al. 1986). The second experiment (Cerretelli 1961) reported data of lung volumes in subjects acclimatised to altitude. The third, and perhaps most significant experiment in the present context (Cerretelli and Margaria 1961), demonstrated that the decrease in maximal oxygen consumption $\left(\dot{V} \mathrm{O}_{2 \max }\right)$ in chronic hypoxia was equivalent to that in acute hypoxia. This implied that the increase in haematocrit or haemoglobin concentration resulting from acclimatisation was unable to increase $\dot{V} \mathrm{O}_{2 \max }$.

After the Kanjut-Sar expedition, Cerretelli had few further experiences in altitude physiology until the 1973 Italian expedition to Mount Everest. Nevertheless, he continued to perform experiments in acute hypoxia. An analysis of blood lactate accumulation (Cerretelli 1967) demonstrated that: (1) the decrease in $\dot{V} \mathrm{O}_{2 \max }$ brings about an equivalent decrease in the work load at which blood lactate accumulation becomes evident, and (2) the maximal blood lactate concentration is unchanged in acute hypoxia, contrary to chronic hypoxia (Dill et al. 1931; Edwards 1936). An investigation of $\dot{V} \mathrm{O}_{2 \max }$ in acute hypoxia supported the hypothesis of central (cardiopulmonary) limitation of $\dot{V} \mathrm{O}_{2 \max }$ in humans (Cerretelli et al. 1967).

\section{Limiting factors to oxygen transport on Mount Everest}

As were many physiologists in the early 1970s, Cerretelli was intrigued by the finding that the decrease in $\dot{V} \mathrm{O}_{2 \max }$ was not the same in acute as in chronic hypoxia (Cerretelli and Margaria 1961), because it appeared to be in contrast with the notion of central $\dot{V} \mathrm{O}_{2 \max }$ limitation and with the observation that altitude acclimatisation implies an increase in haemoglobin concentration. The hypothesis was formulated that cardiovascular oxygen transport may not account for the entire change in $\dot{V} \mathrm{O}_{2 \max }$ in chronic hypoxia. Therefore, on the occasion of the Italian expedition to Mount Everest in 1973, in order to test this hypothesis, Cerretelli conceived and realised the following experiment (Cerretelli 1976): let a man acclimatised to altitude, and thus polycythaemic, breathe at the Everest base camp a gas mixture containing an oxygen partial pressure equivalent to that existing at sea level; if cardiovascular oxygen transport is the factor that limits $\dot{V} \mathrm{O}_{2 \max }$ in chronic hypoxia, this man who was artificially brought back to sea level would have a $\dot{V} \mathrm{O}_{2 \max }$ higher than that measured at sea level before the expedition, because an equivalent maximal cardiac output combined with an increased arterial oxygen concentration would have improved his oxygen transport capacity. If conversely this was not the case, then the limit to $\dot{V} \mathrm{O}_{2 \max }$ would be elsewhere than in cardiovascular oxygen transport. On a fraction of his subjects (group $\mathrm{A}$ in the paper), $\dot{V} \mathrm{O}_{2 \max }$ was measured in Milan before departure (normoxia), at Everest base camp after acclimatisation (chronic hypoxia) and at Everest base camp while breathing a normoxic gas mixture [inspiratory fraction oxygen $\left(\mathrm{FIO}_{2}\right)=0.4$, barometric pressure $=390 \mathrm{mmHg}$, a condition that I would dare to call acute normoxia]. Arterial oxygen concentration $\left(C_{\mathrm{a}} \mathrm{O}_{2}\right)$ was determined from measurements of blood haemoglobin concentration and arterial oxygen saturation. Cardiac output was measured by the $\mathrm{N}_{2}-\mathrm{CO}_{2}$ rebreathing method.

The results are summarised in Table 1 and Fig. 2. Blood haemoglobin concentration obviously increased with acclimatisation, so that, despite the drop in arterial oxygen saturation, $C_{\mathrm{a}} \mathrm{O}_{2}$ levels were slightly higher in chronic hypoxia than in normoxia at maximal exercise. Acute normoxia, of course, then resulted in a huge increase in $C_{\mathrm{a}} \mathrm{O}_{2}$. The decrease in $\dot{V} \mathrm{O}_{2 \max }$ corresponded to what one could have expected at 5,000 m (Pugh et al. 1964). Most significant were the findings in acute normoxia: although the $\dot{V} \mathrm{O}_{2 \max }$ levels increased with respect to the values observed in chronic hypoxia, they did not increase in proportion to $C_{\mathrm{a}} \mathrm{O}_{2}$, but they remained well below the value observed in Milan, in normoxia. Cardiac output was expressed only relative to the value observed in normoxia; however, the values are coherent with those of $\dot{V} \mathrm{O}_{2 \max }$ : maximal cardiac output decreased in chronic hypoxia and, even if a slight increase was observed, it did not come back to the value observed in Milan in acute normoxia. An indirect

Table 1 Results of the 1973 experiment at Everest base camp (Cerretelli 1976). $\dot{V} O_{2 \max }$ Maximal oxygen consumption; $\mathrm{C}_{a} \mathrm{O}_{2}$ arterial oxygen concentration

\begin{tabular}{lllll}
\hline Condition & $\begin{array}{l}\text { Haemoglobin } \\
\left(\mathrm{gl}^{-1}\right)\end{array}$ & $\begin{array}{c}\mathrm{C}_{\mathrm{a}} \mathrm{O}_{2} \\
\left(\mathrm{ml} \mathrm{l}^{-1}\right)\end{array}$ & $\begin{array}{c}\dot{V} \mathrm{O}_{2 \max } \\
\left(1 \mathrm{~min}^{-1}\right)\end{array}$ & $\begin{array}{l}\text { Cardiac } \\
\text { output }(\%)\end{array}$ \\
\hline Normoxia & 150 & 197 & 3.21 & 100 \\
Chronic hypoxia & 206 & 214 & 2.26 & 87 \\
Acute normoxia & 206 & 271 & 2.95 & 92 \\
\hline
\end{tabular}




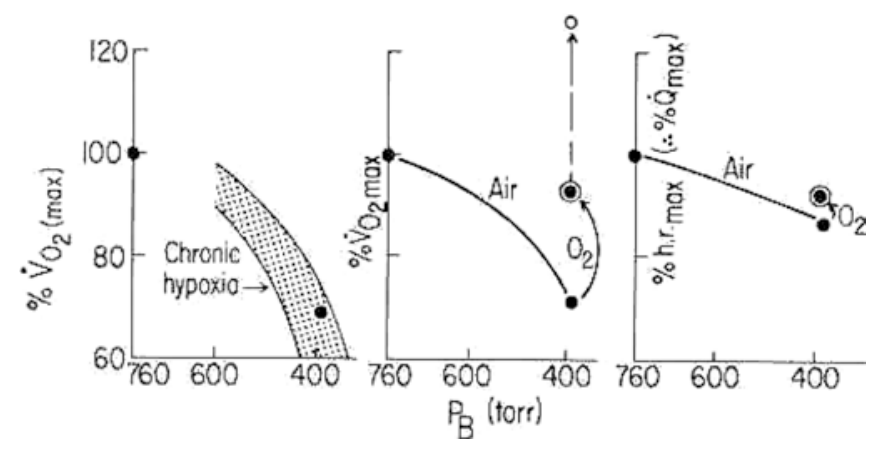

Fig. 2 Left panel Maximal oxygen consumption $\left(\dot{V} \mathrm{O}_{2 \max }\right)$, expressed relative to the value at sea level, set equal to $100 \%$, as a function of barometric pressure. The filled dots refer to the values obtained at Milan (normoxia) and at the Everest base camp after acclimatisation (chronic hypoxia). The dotted area indicates the expected range for $\dot{V} \mathrm{O}_{2 \max }$ values in chronic hypoxia. Middle panel Same as for the left panel. The two values in normoxia and in chronic hypoxia are now connected by a curve. Administration of the hyperoxic mixture at Everest base camp moves the $\dot{V} \mathrm{O}_{2 \max }$ value up to the circled dot, as indicated by the continuous arrow. The open dot indicates the $\dot{V} \mathrm{O}_{2 \max }$ value that Paolo Cerretelli expected to find on average after administration of the hyperoxic mixture, based on the observed increase in blood haemoglobin concentration. The dashed arrow indicates the apparent "lack" of $\dot{V} \mathrm{O}_{2 \max }$. Right panel Heart rate or cardiac output at maximal exercise, expressed relative to the value at sea level, set equal to $100 \%$, as a function of barometric pressure. The values in normoxia and in chronic hypoxia (filled dots) are connected by a curve. Administration of the hyperoxic mixture at Everest base camp moves the $V \mathrm{O}_{2 \max }$ value up to the circled dot. Redrawn from Cerretelli 1976

observation pointing in the same direction was made a few years earlier by Pugh et al. (1964): while breathing oxygen at $150 \mathrm{mmHg}$ at $5,800 \mathrm{~m}$ after acclimatisation, two of their subjects were able to sustain a given supramaximal power for $4 \mathrm{~min}$ instead of $6 \mathrm{~min}$, as at sea level. This observation was overlooked by Pugh, but it did not escape Cerretelli, who was thinking along those lines.

These results were discussed as being indicative of the fact that cardiovascular oxygen transport is not the factor that limits $\dot{V} \mathrm{O}_{2 \max }$ in chronic hypoxia. Since the investigated respiratory variables, not reported here, were unaffected by chronic hypoxia, the lungs (ventilation and/or diffusion) were not considered as an alternative limiting factor. So, Cerretelli suggested that "the limiting factors for aerobic work performance are peripheral". And in the periphery, he directed his attention to capillary perfusion or diffusion, since, based on observations on rats (Gold et al. 1973), he argued that there could not be changes in cell respiration due to chronic hypoxia exposure. Curiously enough, the failure to observe an increase in $\dot{V} \mathrm{O}_{2 \max }$ in acute normoxia above the value measured in Milan was taken to be an analogous of the failure to observe an increase in $\dot{V} \mathrm{O}_{2 \max }$ proportional to that in inspired oxygen pressure in hyperoxia (Bannister et al. 1954; Margaria et al. 1961, 1972; Fagraeus et al. 1973). In a book chapter written a few years later, commenting the same results, Cerretelli (1982) wrote: "the failure of sudden hyperoxia to raise
$\dot{V} \mathrm{O}_{2 \max }$ in acclimatised lowlanders to sea level or even higher values in the absence of a drastic reduction of maximal cardiac output could be explained by a reduction of effective blood flow to the working muscles".

\section{Critique of a paper, 27 years later}

When Cerretelli wrote his paper, the subject of the factors that limit $\dot{V} \mathrm{O}_{2 \max }$ was looked at under an either/or perspective. The exercise physiology community was divided between those who were convinced that the limits were imposed by central circulation (cardiovascular oxygen transport) and those who believed that the limits were of muscular origin. Indeed the majority supported the former statement (Åstrand 1952; Margaria et al. 1965; Holmgren and Åstrand 1966; Ekblom 1969; Saltin 1973; Rowell 1974; just to cite publications preceding Cerretelli's paper), because $\dot{V} \mathrm{O}_{2 \max }$ was: (1) higher in endurance athletes than in non-athletes (Saltin and Astrand 1967), (2) proportional to maximal cardiac output (Åstrand et al. 1964; Ekblom and Hermansen 1968), (3) increased by endurance exercise training (Ekblom et al. 1968). Most significant in this context, and even considered conclusive by some, were the first experiments showing an increase in $\dot{V} \mathrm{O}_{2 \max }$ after autologous blood reinfusion (Ekblom et al. 1972) and the parallel of such an increase with that in maximal cardiac output (Ekblom et al. 1976). When he wrote his paper, Cerretelli was probably unaware of the latter article, which had been published just 2 months earlier in the same journal, when his article was already in press. This circumstance may explain why he underestimated the significance of autologous blood reinfusion in his paper's discussion.

We must recognise that Cerretelli's reasoning was logical and coherent with the way of thinking of that time. To him, the fact that $\dot{V} \mathrm{O}_{2 \max }$ did not increase in acute normoxia above the level attained in hypoxia could only mean that central circulation was not limiting. Thus, it was logical to look elsewhere, and think of a distal site of limitation. When Cerretelli looked into muscle, however, he excluded oxidative capacity as a possible site of limitation, and he did this on the basis of an observation made on small animals. Other more convincing yet neglected data were available that seemed to support the same viewpoint. In particular, Reynafarjee (1962) reported an increase in myoglobin concentration and in oxidative enzyme activity in Andean altitude natives. Thanks essentially to Reynafarjee's work, the belief that oxidative capacity was to increase in chronic hypoxia was very strong, so strong that, when Reinhold Messner conquered Mount Everest without using supplementary oxygen, John West explained this extraordinary achievement by hypothesising an extremely high oxidative capacity (West and Wagner 1980; West 1983), and so strong that finally Hochachka et al. (1983) constructed a keen interpretative hypothesis around this notion. Their point was that animals living 
in chronic hypoxia had to face a major problem, namely "how to maintain an acceptably high scope for aerobic metabolism in the face of the reduced oxygen availability of the atmosphere", and they proposed that this could be achieved by increasing the capacity for oxygen transport and the capacity for oxidative metabolism.

The way of looking at $\dot{V} \mathrm{O}_{2 \max }$ limitation has drastically changed in subsequent years. After Taylor and Weibel (1981) had resumed work on the oxygen conductance equation and had applied it to the condition of maximal exercise, multifactorial models of $\dot{V} \mathrm{O}_{2 \max }$ limitation were developed. The first and most comprehensive of these models was conceptually proposed by di Prampero (1985), algebraically formulated by di Prampero and Ferretti (1990) and later expanded to cover hypoxia (Ferretti and di Prampero 1995). This model implies that: (1) oxygen flows from ambient air to mitochondria along a number of resistances in-series; (2) each of these resistances provides a measurable fraction of $\dot{V} \mathrm{O}_{2 \max }$ limitation, the greatest of which is accounted for by cardiovascular oxygen transport $(\sim 60-70 \%)$; (3) the system is non-linear, because of the shape of the oxygen equilibrium curve, so that the lung (ventilation and/or diffusion), that is not limiting in normoxia, becomes limiting in hypoxia; (4) the role played by muscular factors (either diffusive or metabolic) is minor both in normoxia and in hypoxia. Other concurrent models, but generated after the same starting concept, were also developed (Wagner 1993). It has now become a generally accepted notion that $\dot{V} \mathrm{O}_{2 \max }$ is limited not by a single factor (monofactorial theory), as believed 30 years ago, but by the simultaneous action of multiple factors (multifactorial theory).

In the contemporary cultural context, I would propose a different interpretation of Cerretelli's paper. According to di Prampero and Ferretti (1990), the cardiovascular resistance to oxygen flow $\left(R_{\mathrm{q}}\right)$ is equal to:

$R \mathrm{q}=(G \mathrm{q})^{-1}=(\dot{Q} \beta \mathrm{b})^{-1}$

Where $\dot{Q}$ is the cardiac output, $G_{\mathrm{q}}$ is the equivalent conductance and $\beta_{\mathrm{b}}$ is the oxygen transport coefficient of blood. This in turn corresponds to the average slope of the oxygen equilibrium curve as:

$\beta_{\mathrm{b}}=\left(C_{\mathrm{a}} \mathrm{O}_{2}-C_{\mathrm{v}}-\mathrm{O}_{2}\right)\left(P_{\mathrm{a}} \mathrm{O}_{2}-P_{\mathrm{v}} \mathrm{O}_{2}\right)^{-1}$

where $C$ and $P$ indicate the concentrations and pressures of oxygen, respectively, in arterial (a) and mixed venous $(\overline{\mathrm{v}})$ blood. Administering oxygen at $150 \mathrm{mmHg}$ to Cerretelli's subjects at Everest base camp was tantamount to changing three parameters pertaining to the oxygen conductance equation: (1) increase the overall oxygen gradient, because he changed the inspired oxygen pressure; (2) slightly increase the maximal cardiac output (it was measured indeed); and (3) to decrease the factor $\beta_{\mathrm{b}}$. In fact, the increase in inspired oxygen pressure brought about a subsequent increase in alveolar and arterial oxygen pressures, so that the arterial blood point was moved onto the flat part of the oxygen equilibrium curve. Since the mixed venous blood point on the oxygen equilibrium is only slightly displaced under these conditions, there is then a dramatic change in the average slope of the oxygen equilibrium curve, and thus in $\beta_{\mathrm{b}}$. According to Eq. 1, this means a reduction of $G_{\mathrm{q}}$ with a consequent increase in $\mathrm{R}_{\mathrm{q}}$. To sum up, the administration of oxygen at $150 \mathrm{mmHg}$ did not induce a $\dot{V} \mathrm{O}_{2 \max }$ increase proportional to that in the overall oxygen gradient, because, due to the shape of the oxygen equilibrium curve, the latter increase was inevitably accompanied by a concomitant reinforcement of the cardiovascular resistance to oxygen flow. These are exactly the same reasons why $\dot{V} \mathrm{O}_{2 \max }$ does not increase in hyperoxia and why subjects with a high $\dot{V} \mathrm{O}_{2 \max }$ in normoxia, who are subjected to arterial oxygen desaturation (Dempsey et al. 1984), undergo a greater decrease in $\dot{V} \mathrm{O}_{2 \max }$ in hypoxia (Ferretti et al. 1997). Indeed Cerretelli's experiment provides nothing but a brilliant confirmation of the predominant role of cardiovascular oxygen transport in limiting $\dot{V} \mathrm{O}_{2 \max }$ ! Since $\dot{V} \mathrm{O}_{2 \max }$ did not return to the level measured in Milan before the expedition, it is likely that the peripheral (muscular) resistances to oxygen flow factors, though smaller than $R_{\mathrm{q}}$, are larger than in normoxia. However, this by no means implies that the fractional limitation to $\dot{V} \mathrm{O}_{2 \max }$ in chronic hypoxia imposed by peripheral factors is increased.

\section{Consequences: the study of muscle structure}

Finally, a paper was published that demonstrated the role of cardiovascular oxygen transport in limiting $\dot{V} \mathrm{O}_{2 \max }$ and this prompted a series of innovative research projects on muscle structural adaptation to altitude exposure! This was not Cerretelli's original intention, because he was candidly convinced that muscle oxidative capacity had nothing to do with it, and proposed to investigate muscle blood flow and capillarity. Nobody studied muscle blood flow in chronic hypoxia. Cerretelli et al. (1984) measured muscle blood flow in a group of climbers upon return from an altitude expedition, but the only notable finding was a slower blood flow adaptation at light exercise onset. I guess that the keyword leading to muscle structural studies could have been capillarity, which can be determined by histochemical or morphometric methods on muscle biopsy samples. So I cannot say whether the evolution of research after the publication of Cerretelli's paper was serendipitous or not, yet it is a fact that, in apparent contrast with the paper's conclusions, his attention turned to the study of muscle morphometry. To this aim, Cerretelli, who had then moved to Geneva, set up a collaboration with Hans Hoppeler and Hans Howald.

Hoppeler and Howald, together with Ewald Weibel, initiated the morphometric study of human muscle in the early 1970s (Hoppeler et al. 1973). A few years later, in collaboration with Dick Taylor, Weibel organised a major study on the structural characteristics and limits 
of the mammalian respiratory system that resulted in a remarkable series of publications in Respiration Physiology (Taylor and Weibel 1981). Hoppeler was responsible for muscle morphometric studies, Howald for muscle enzymatic activity studies. They were both fascinated by Messner's achievement, and attracted by West's hypothesis to explain it.

The collaboration between Cerretelli and Hoppeler and Howald was inevitable and led to several investigations on the structural and biochemical characteristics of muscle in chronic hypoxia. Elite climbers (Oelz et al. 1986), climbers before and after acclimatisation (Hoppeler et al. 1990; Howald et al. 1990), Sherpas (Kayser et al. 1991), Tibetans (Kayser et al. 1996) and Andean natives (Desplanches et al. 1996) were studied. Others also joined this line of research, investigating the participants in Operation Everest II (Green et al. 1989; McDougall et al. 1991) or other acclimatised subjects (Poole and Mathieu-Costello 1989). The common finding of all these studies was the remarkable reduction of muscle oxidative capacity measured both from the measurement of muscle mitochondrial volume density or mass and from muscle oxidative enzyme activities (see Table 2). These observations were opposite to what Paolo, and all altitude physiologists, expected. Furthermore, they were so univocal and coherent that they led to the dismissal of Hochachka's interpretative hypothesis (Hochachka et al. 1983), at least as far as humans were concerned. In addition, these studies invariably showed an increase in muscle capillary density that may have come more from muscle fibre restriction than from capillary neoformation. This finding implies a reduction in muscle diffusion distances that facilitates oxygen diffusion from capillaries to mitochondria. This in turn compensates for the loss of mitochondrial oxidative capacity, so that in the end, the ensemble of the peripheral resistances to oxygen flow remains essentially unchanged in altitude-adapted humans compared with non-acclimatised normoxic lowlanders.

To sum up, a remarkable paper that demonstrated how cardiovascular oxygen transport limits $\dot{V} \mathrm{O}_{2 \max }$, and that proposed muscle blood flow as the factor that limits
$\dot{V} \mathrm{O}_{2 \max }$ at altitude, prompted a series of experiments that unambiguously showed the loss of muscle oxidative capacity as the most prominent effect of chronic hypoxia on human muscle structure and function. This story prevents one from thinking that a coherent linear evolution of our scientific knowledge is a consequence of a logical series of hypotheses and refutations. It rather puts forward a great deal of serendipity, accidental, chance and logical misdemeanour that fits well with Feyerabend's anarchic theory of the evolution of scientific knowledge (Feyerabend 1975).

\section{The recent years}

By the end of the 1980s, Cerretelli took over the scientific responsibility for the permanent Italian altitude laboratory at Mount Everest (generally referred to as the Pyramid), where he organised several physiological research projects. Most of the experiments at the Pyramid have indeed been carried out by his pupils and veritable heirs in the field: Bruno Grassi (Milan), Bengt Kayser (Geneva) and Marco Narici (Manchester). Without summarising all the work carried out at the Pyramid, I would just mention a project that illuminates Cerretelli's cultural background. It deals with the subject of the socalled lactate paradox.

Dill et al. (1931) and Edwards (1936) were the first to report that the maximal blood lactate concentration attained at exhaustion from an incremental exercise test was reduced in chronic hypoxia, an observation confirmed by many, including Paolo, who reported this phenomenon on Caucasians and Sherpas (Cerretelli et al. 1982). By contrast, the maximal blood lactate concentration was unchanged in acute hypoxia (Cerretelli 1967; Cerretelli et al. 1982). This state of things was viewed as paradoxical (West 1986; Hochachka 1989), and the term lactate paradox was eventually created to define it (Hochachka 1989).

Numerous hypotheses have been formulated to explain this phenomenon. Paolo postulated that it could be due to a reduced buffer capacity in chronic hypoxia (Cerretelli et al. 1982), and provided "cute" experimental

Table 2 Morphometric determinations of muscle oxidative capacity and capillary density in chronic hypoxia. All the data reported in this table were obtained in the electron microscope laboratory of the Institute of Anatomy, University of Bern

\begin{tabular}{llll}
\hline Subjects & Capillary density $\left(\mathrm{mm}^{-2}\right)$ & Mitochondrial density $(\%)$ & Reference \\
\hline Untrained Caucasians & 373 & 4.33 & Hoppeler et al. 1985 \\
& 379 & 5.15 & Desplanches et al. 1993 \\
Trained Caucasians & 481 & 6.08 & Hoppeler et al. 1985 \\
& 395 & 6.99 & Desplanches et al. 1993 \\
Climbers before expedition $^{\mathrm{b}}$ & $483^{\mathrm{b}}$ & $5.85^{\mathrm{b}}$ & Hoppeler et al. 1990 \\
Climbers after expedition $^{\mathrm{b}}$ & $538^{\mathrm{a}, \mathrm{b}}$ & $4.76^{\mathrm{a}, \mathrm{b}}$ & Hoppeler et al. 1990 \\
Elite climbers $_{\text {Sherpas }}$ & $542^{\mathrm{a}}$ & $4.95^{\mathrm{a}}$ & Oelz et al. 1986 \\
Tibetans & $467^{\mathrm{a}}$ & $3.96^{\mathrm{a}}$ & Kayser et al. 1991 \\
La Paz natives & - & $3.99^{\mathrm{a}}$ & Kayser et al. 1996 \\
& $405^{\mathrm{a}}$ & $3.94^{\mathrm{a}}$ & Desplanches et al. 1996
\end{tabular}

\footnotetext{
${ }^{a}$ Subjects adapted to chronic hypoxia

${ }^{\mathrm{b}}$ The same group of climbers, investigated before and after a Himalayan expedition
} 
evidence disproving this hypothesis (Kayser et al. 1993). A reduction in chronic hypoxia of the maximal rate at which lactate can be accumulated in blood, corresponding to the maximal lactic power (Margaria et al. 1964) was demonstrated (Grassi et al. 1995). The progressive reversibility of the lactate paradox phenomenon upon return to sea level as acclimatisation is lost was also demonstrated (Grassi et al. 1996). A lower maximal blood lactate concentration in chronic hypoxia was documented also after supramaximal exercise of $30 \mathrm{~s}$ duration, but not of $10 \mathrm{~s}$ duration (Grassi et al. 2001). The hypothesis that exercise time to exhaustion may play some role was formulated.

These experiments did not pretend to find a solution to the lactate paradox problem-and perhaps there is no solution to what is not a physio-logical paradox. However, the results agree with the observation of a reduced net lactate release from working muscles in chronic hypoxia (Bender et al. 1989; Brooks et al. 1992, 1998). In my view, these data altogether support the hypothesis that the lactate paradox may reflect a reduction of proton transport outside the muscle fibre, perhaps due to a reduced activity of the lactate-proton co-transporter. More recently, Saltin's group has shown that there are no differences in maximal blood lactate concentration between chronic hypoxia and normoxia if acclimatisation to altitude is prolonged beyond 6 weeks (Lundby et al. 2000; van Hall et al. 2001), suggesting that the lactate paradox may be a transient phenomenon. This has led to a slight modification of this hypothesis, as the possibility of a progressive upregulation of the lactate-proton co-transporter with time of acclimatisation had to be postulated (van Hall et al. 2001), but not to its refutation. Cerretelli's work has contributed a "major brick to this construction".

\section{The future}

Paolo Cerretelli is now 70 years old. He is a serene professor of physiology at Milan. He is still active in high-altitude research. He is turning his attention to genetic aspects of altitude adaptation, and he is investigating the possibility of a permanent trans-generational adaptation to hypoxia in lowlander Tibetans of high-altitude ancestry. $\mathrm{He}$ is associated with a project aimed at studying human muscle proteome in chronic hypoxia. His vitality is impressive, his enthusiasm for research unaltered, his motivation as strong as ever. I am confident that that the future holds for him the same satisfaction that he has had so far. Happy birthday Paolo, have a long life, and as happy as you have had so far.

\section{References}

Åstrand PO (1952) Experimental studies of physical working capacity in relation to sex and age. Munksgaard, Copenhagen
Åstrand PO, Cuddy TE, Saltin B, Stenberg J (1964) Cardiac output during submaximal and maximal work. J Appl Physiol 19:268274

Bannister RG, Cunningham DJC (1954) The effects on respiration and performance during exercise of adding oxygen to the inspired air. J Physiol (Lond) 125:118-137

Bender PR, Groves BM, McCullough RE, McCullough RG, Trad L, Young AJ, Cymerman A, Reeves JT (1989) Decreased exercise muscle lactate release after high altitude acclimatization. J Appl Physiol 67:1456-1462

Brooks GA, Wolfel EE, Groves BM, Bender PR, Butterfield GE, Cymerman A, Mazzeo R, Sutton JR (1992) Muscle accounts for glucose disposal but not blood lactate appearance during exercise after acclimatization to $4,300 \mathrm{~m}$. J Appl Physiol 72:2435-2445

Brooks GA, Wolfel EE, Butterfield GE, Cymerman A, Roberts AC, Mazzeo R, Reeves JT (1998) Poor relation between arterial [lactate] and leg net release during exercise at 4,300 $\mathrm{m}$ altitude. Am J Physiol 275:R1192-R1201

Cerretelli P (1959) Esistenza di una permanente stimolazione ipossica del centro respiratorio in individui acclimatati a quote di 5000-7500 m. s.l.m. (Himalaya). Atti Congresso Internazionale di Medicina Aeronautica e Spaziale, Rome, pp 1-8

Cerretelli P (1961) Some aspects of the respiratory function in man acclimatized to high altitude (the Himalayas). Int Z Angew Physiol 18:386-392

Cerretelli P (1967) Lactacid $\mathrm{O}_{2}$ debt in chronic and acute hypoxia. In: Margaria R (ed) Exercise at altitude. Excerpta Medica, Amsterdam, pp 58-64

Cerretelli P (1976) Limiting factors to oxygen transport on Mount Everest. J Appl Physiol 40:658-667

Cerretelli $\mathrm{P}$ (1982) $\mathrm{O}_{2}$ breathing at altitude: effects on maximal performance. In: Brendel W, Zinc RA (eds) High altitude physiology and medicine. Springer, Berlin Heidelberg New York pp 9-15

Cerretelli P, Margaria R (1961) Maximum oxygen consumption at altitude. Int Z Angew Physiol 18:460-464

Cerretelli P, Bordoni U, Debijadji R, Saracino F (1967) Respiratory and circulatory factors affecting the maximal aerobic power in hypoxia. Arch Fisiol 65:344-357

Cerretelli P, Veicsteinas A, Marconi C (1982) Anaerobic metabolism at high altitude: the lactacid mechanism. In: Brendel W, Zinc RA (eds) High altitude physiology and medicine. Springer, Berlin Heidelberg New York, pp 94-102

Cerretelli P, Marconi C, Dériaz O, Giezendanner D (1984) After effects of chronic hypoxia on cardiac output and muscle blood flow at rest and exercise. Eur J Appl Physiol 53:92-96

Dejours P, Girard F, Labrousse Y, Teillac A (1959) Etude de la régulation de la ventilation de repos chez l'homme en haute altitude. Rev Fr Etud Clin Biol 4:115-127

Dempsey JA, Hanson PG, Henderson KS (1984) Exercise-induced arterial hypoxaemia in healthy human subjects at sea level. J Physiol (Lond) 355:161-175

Desplanches D, Hoppeler H, Linossier MT, Denis C, Claassen H, Dormois D, Lacour JR, Geyssant A (1993) Effects of training in normoxia and normobaric hypoxia on human muscle ultrastructure. Pflugers Arch 425:263-267

Desplanches D, Hoppeler H, Tüscher L, Mayet MH, Spielvogel H, Ferretti G, Kayser B, Leuenberger M, Grünefelder A, Favier R (1996) Muscle tissue adaptations of high altitude natives to training in chronic hypoxia or acute normoxia. J Appl Physiol 81:1946-1951

Dill DB, Edwards HT, Folling A, Oberg SA, Pappenheimer AM, Talbot JH (1931). Adaptations of the organism to changes in oxygen pressure. J Physiol (Lond) 71:47-63

Di Prampero PE (1985) Metabolic and circulatory limitations to $\dot{V} \mathrm{O}_{2 \max }$ at the whole animal level. J Exp Biol 115:319-331

Di Prampero PE, Ferretti G (1990) Factors limiting maximal oxygen consumption in humans. Respir Physiol 80:113-128

Edwards HT (1936) Lactic acid in rest and work at high altitude. Am J Physiol 116:367-375

Ekblom B (1969) The effect of physical training on oxygen transport system in man. Acta Physiol Scand Suppl 328:1-45 
Ekblom B, Hermansen L (1968) Cardiac output in athletes. J Appl Physiol 25:619-625

Ekblom B, Astrand PO, Saltin B, Stenberg J, Wallström B (1968) Effect of training on circulatory response to exercise. J Appl Physiol 24:518-528

Ekblom B, Goldbarg AN, Gullbring B (1972) Response to exercise after blood loss and reinfusion. J Appl Physiol 33:175-180

Ekblom B, Wilson G, Astrand PO (1976) Central circulation during exercise after venesection and reinfusion of red blood cells. J Appl Physiol 40:379-383

Fagraeus L, Karlsson J, Linnarsson D, Saltin B (1973) Oxygen uptake during maximal work at lowered and raised ambient air pressures. Acta Physiol Scand 87:411-421

Ferretti G, di Prampero PE (1995) Factors limiting maximal $\mathrm{O}_{2}$ consumption: effects of acute changes in ventilation. Respir Physiol 99:259-271

Ferretti G, Moia C, Thomet JM, Kayser B (1997) The decrease of maximal oxygen consumption during hypoxia in man: a mirror image of the oxygen equilibrium curve. J Physiol (Lond) 498:231-237

Feyerabend P (1975) Against method. Verso, London

Gold AJ, Johnson TF, Costello LC (1973) Effects of altitude stress on mitochondrial function. Am J Physiol 224:946-949

Grassi B, Ferretti G, Kayser B, Marzorati M, Colombini A, Marconi C, Cerretelli P (1995) Maximal rate of blood lactate accumulation during exercise at high altitude in humans. J Appl Physiol 79:331-339

Grassi B, Marzorati M, Kayser B, Bordini M, Colombini A, Conti M, Marconi C, Cerretelli P (1996) Peak blood lactate and blood lactate vs. workload during acclimatization to $5050 \mathrm{~m}$ and in the deacclimatization. J Appl Physiol 80:685-692

Grassi B, Mognoni P, Marzorati M, Mattiotti S, Marconi C, Cerretelli P (2001) Power and peak blood lactate at $5050 \mathrm{~m}$ with 10 and 30 s "all out" cycling. Acta Physiol Scand 172:189-194

Green HJ, Sutton JR, Cymerman A, Young PM, Houston CS (1989) Operation Everest II: Adaptations in human skeletal muscle. J Appl Physiol 66:2454-2461

Hochachka PW (1989) The lactate paradox: analysis of the underlying mechanisms. Ann Sports Med 4:184-188

Hochachka PW, Stanley C, Merkt J, Sumar-Kalinowski J (1983) Metabolic meaning of elevated levels of oxidative enzymes in high altitude adapted animals: an interpretive hypothesis. Respir Physiol 52:303-313

Holmgren A, Astrand PO (1966) DL and the dimensions and functional capacities of the $\mathrm{O}_{2}$ transport system in humans. J Appl Physiol 21:1463-1470

Hoppeler H, Luethi P, Claassen E, Weibel ER, Howald H (1973) The ultrastructure of the normal human skeletal muscle. A morphometric analysis of untrained men, women, and welltrained orienteers. Pflugers Arch 334:217-232

Hoppeler H, Howald H, Conley K, Lindstedt SL, Claassen H, Vock P, Weibel ER (1985) Endurance training in humans: aerobic capacity and structure of skeletal muscle. J Appl Physiol 59:320-327

Hoppeler H, Kleinert E, Schlegel C, Claassen H, Howald H, Cerretelli P (1990) Muscular exercise at high altitude. II. Morphological adaptation of skeletal muscle to chronic hypoxia. Int J Sports Med 11 [Suppl 1]: S3-S9

Howald H, Pette D, Simoneau JA, Uber A, Hoppeler H, Cerretelli P (1990) Muscular exercise at high altitude. III. Effects of chronic hypoxia on muscle enzyme activity. Int J Sports Med 11 [Suppl 1]: S10-S14
Kayser B, Hoppeler H, Claassen H, Cerretelli P (1991) Muscle structure and performance capacity of Himalayan Sherpas. J Appl Physiol 70:1938-1942

Kayser B, Ferretti G, Grassi B, Binzoni T, Cerretelli P (1993) Maximal lactic capacity at high altitude. Effect of bicarbonate loading. J Appl Physiol 75:1070-1074

Kayser B, Hoppeler H, Desplanches D, Broers B, Marconi C, Cerretelli P (1996) Muscle ultrastructure and biochemistry of lowland Tibetans. J Appl Physiol 81:419-425

Lundby C, Saltin B, van Hall G (2000) The "lactate paradox", evidence for a transient change in the course of acclimatization to severe hypoxia in lowlanders. Acta Physiol Scand 170:265269

Margaria R, Cerretelli P, Marchi S, Rossi L (1961) Maximum exercise in oxygen. Int Z Angew Physiol 18:465-467

Margaria R, Cerretelli P, Mangili F (1964) Balance and kinetics of anaerobic energy release durino strenuous exercise in man J Appl Physiol 19:623-628

Margaria R, Mangili F, Cuttica F, Cerretelli P (1965) The kinetics of the oxygen consumption at the onset of muscular exercise in man. Ergonomics 8:49-54

Margaria R, Camporesi E, Aghemo P, Sassi G (1972) The effect of $\mathrm{O}_{2}$ breathing on maximal aerobic power. Pflugers Arch 336:225-235

McDougall JD, Green HJ, Sutton JR, Coates G, Cymerman A, Young P, Houston CS (1991) Operation Everest II. Structural adaptations in skeletal muscle in response to extreme simulated altitude. Acta Physiol Scand 142:421-427

Oelz O, Howald H, di Prampero PE, Hoppeler H, Claassen H, Jenni R, Bühlmann A, Ferretti G, Brückner JC, Veicsteinas A, Gussoni M, Cerretelli P (1986) Physiological profile of world class high altitude climbers. J Appl Physiol 60:1734-1742

Poole DC, Mathieu-Costello O (1989) Skeletal muscle capillary geometry: adaptation to chronic hypoxia. Respir Physiol 77:2130

Pugh LGCE, Gill MB, Lahiri S, Milledge JS, Ward MP, West JB (1964) Muscular exercise at great altitudes. J Appl Physiol 19:431-440

Reynafarjee (1962) Myoglobin content and enzymatic activity of muscle and altitude adaptation. J Appl Physiol 17:301-305

Rowell LB (1974) Human cardiovascular adjustments to exercise and thermal stress. Physiol Rev 54:75-159

Saltin B (1973) Oxygen transport by the circulatory system during exercise in man. In: Keul $\mathbf{J}$ (ed) Limiting factors of physical performance. Thieme, Stuttgart, pp 235-252

Saltin B, Astrand PO (1967) Maximal oxygen consumption in athletes. J Appl Physiol 23: 353-358

Taylor CR, Weibel ER (eds) (1981) Design of the mammalian respiratory system. Respir Physiol 44:1-164

Van Hall G, Calbet JAL, Sondergaard H, Saltin B (2001) The reestablishment of the normal blood lactate response to exercise in humans after prolonged acclimatization to altitude. J Physiol (Lond) 536:963-975

Wagner PD (1993) Algebraic analysis of the determinants of $\dot{V} \mathrm{O}_{2 \max }$. Respir Physiol 93:221-237

West JB (1983) Climbing Mount Everest without oxygen: an analysis of maximal exercise during extreme hypoxia. Respir Physiol 52:265-279

West JB (1986) Lactate during exercise at extreme altitude. Fed Proc 45:2953-2957

West JB, Wagner PD (1980) Predicted gas exchange on the summit of Mt. Everest. Respir Physiol 42:1-16 